\title{
The need to promote public health in the field of illicit drug use
}

\author{
Mark A. Wainberg
}

$\infty$

See related articles pages 1385 and 1399

I $\mathrm{n}$ this issue of the $C M A J, 2$ important articles shed light on policies that Canada should adopt to stem the spread of HIV infection among users of illicit drugs. In the first article, Evan Wood and colleagues of the BC Centre for Excellence in HIV/AIDS provide a summary of the findings from the evaluation of the supervised safer injecting facility established in Vancouver in September 2003 (page I399). ${ }^{1}$ Individuals who use this site inject pre-obtained illicit drugs under medical supervision in conditions that assure safer use of clean needles and syringes than might otherwise be expected.

Recently, the federal government announced a limited extension of the waiver of law that will enable the Vancouver safer injecting facility to remain open only until the end of 2007 instead of the additional $3^{1 / 2}$ years that had been requested. This waiver of law is necessary because both the injection drug users (IDUs) and the medical supervisors at the facility are theoretically engaged in the abuse of illicit substances and could otherwise be charged with a criminal offence. Although Health Minister Tony Clement stated that further evaluation of the site was necessary, ${ }^{2}$ the government cancelled a grant that would have permitted further evaluation. Funding for the facility itself is provided by Vancouver Coastal Health, an agency of the BC provincial government.

The Vancouver safer injecting facility follows on the experience of similar facilities that have existed over the past decade in Australia and Europe. Numerous studies have shown that programs promoting the use of clean syringes and needles and needle/syringe exchange have resulted in reduced rates of transmission of HIV and other infectious agents and have saved lives. ${ }^{3-6}$

According to the findings summarized by Wood and colleagues, the Vancouver safer injecting facility has been a great success. About 5000 unique IDUs used the facility during its first year of operation. Heroin and cocaine were used in about $40 \%$ and $30 \%$ of injections respectively. Virtually all of the facility users expressed satisfaction with the site and its staff.

Advocates of the Vancouver facility hoped that it might play an important role in promoting public health by both discouraging the continued use of illicit drugs and providing education about safer injecting and prevention of HIV infection and other bloodborne diseases. The program appears to have been successful in this role. The rate of syringe sharing decreased after the facility opened, and only among facility users. In addition, use of the facility was associated with reduced syringe lending by HIV-positive IDUs and reduced syringe borrowing by HIV-negative IDUs. It was also associated with other safe injection practices, including decreased reuse of syringes, increased use of sterile water for formulation of injected drugs

and increased alcohol swabbing of injection sites. The facility also proved to be a valuable referral centre for addiction counselling and other community resources. Individuals who visited the facility at least once per week reported an increased willingness to enter a detoxification program. Hence, existence of the safer injecting facility may ultimately lead to decreased use of illicit drugs. No negative consequences, such as increased rates of crime, were reported.

In another article in this issue, Fischer and colleagues report on their assessment of opioid use patterns and related social and health indicators in the multisite OPICAN cohort (page 1385). ${ }^{7}$ The cohort was established in $200 \mathrm{I}$ and continues to enroll regular illicit opioid users who were not receiving methadone maintenance treatment at the time of recruitment. Fischer and colleagues found that, as of the 2005 follow-up assessment of the cohort, there was an important shift away from heroin use in most of the 7 study sites and that use of other opioids, including hydromorphone (Dilaudid), morphine (e.g., Ms Contin) and oxycodone (OxyContin, Percocet, Percodan), has become the predominant form of opioid abuse. Their findings are substantiated by recent findings from the United States. Their data indicate that a substantial proportion of prescription opioids were reportedly obtained directly or indirectly from hospitals and other medical sources. A common conclusion that can be drawn from the studies by Wood and Fischer and their colleagues is that the risk of drug overdose and transmission of HIV infection and other viral infections will, of course, be increased if drug injections are carried out under conditions of syringe and needle sharing. ${ }^{8-10}$

The findings reported by Wood and Fischer and their colleagues highlight the fact that Canada continues to be plagued by problems of illicit drug use that not only threaten the health of individuals but also the general public health through the transmission of HIV and other infectious agents. By all accounts, the Vancouver safer injecting facility has reached its goal of reducing the risk of overdose among IDUs who use the facility at least once a week. Existence of the facility has also resulted in substantial increases in the number of facility users who have entered detoxification programs and have modified their HIV risk behaviours. The study by Fischer and colleagues on changes in illicit opioid use away from heroin toward prescription opioids indicates a need for constant vigilance and possible adjustments to opioid addiction treatment programs.

The success of the Vancouver safer injecting facility indicates that the facility should not be shut down. Instead, the federal government should draft legislation to allow other such facilities to operate elsewhere in Canada. Also, it should support the evaluation of a safer injecting facility in the con- 
text of a "wet shelter," which provides alcohol and shelter to homeless alcoholic people.

Why would the government on the one hand announce that additional time is needed to study the potential success of the Vancouver safer injecting facility and on the other hand eliminate the funding needed for such evaluations? Government policies regarding safer injecting facilities should be driven by consideration of evidence-based medicine and social policy and of findings indicating whether such programs are successful. By all criteria, the Vancouver facility has both saved lives and contributed toward the decreased use of illicit drugs and the reduced spread of HIV infection and other bloodborne infections. One hopes that the current government under Stephen Harper, which has been in office since only February 2006, will be willing to learn and to revisit this issue in the interest of public health. Government leaders should understand that allowing safer injecting facilities to operate in other Canadian cities is consistent with conservative values aimed at diminishing illicit drug use and HIV transmission. Moreover, studies conducted by Health Canada scientists advocate harm reduction strategies as important means of preventing HIV transmission. ${ }^{11}$

This article has been peer reviewed.

Mark Wainberg is Professor of Medicine at McGill University and Director of the McGill University AIDS Centre, Jewish General Hospital, Montréal, Que.

Competing interests: None declared.

\section{REFERENCES}

I. Wood E, Tyndall MW, Montaner IS, et al. Summary of findings from the evaluation of a pilot medically supervised safer injecting facility. CMAJ 2006;175(II): I399-404.

2. CBC News. B.C. injection site to continue operating, for now. 2006 Sept I. Available: www.cbc.ca/canada/story/2006/og/or/injection-announcement.html (accessed 2006 Oct 24).

3. Des Jarlais DC, Hagan H, Friedman SR, et al. Maintaining low HIV seroprevalence in populations of injecting drug users. JAMA I995;274:1226-3I.

4. Doherty MC, Junge B, Rathouz P, et al. The effect of a needle exchange program on numbers of discarded needles: a 2-year follow-up. Am J Public Health 2000;90: 936-9.

5. Kimber J, Dolan K, Wodak A. Survey of drug consumption rooms: service delivery and perceived public health and amenity impact. Drug Alcohol Rev 2005;24: 2I-4.

6. Rhodes T, Kimber J, Small W, et al. Public injecting and the need for "safer environment interventions" in the reduction of drug-related harm. Addiction 2006; I0I: 1384-93.

7. Fischer B, Rehm J, Patra J, et al. Changes in illicit opioid use across Canada. CMAJ 2006;I75(II):I385-7.

8. Strike C, Gnam W, Urbanoski K, et al. Factors predicting 2-year retention in methadone maintenance treatment for opioid dependence. Addict Behav 2005;30: I025-8.

9. Tyndall MW, Currie S, Spittal P, et al. Intensive injection cocaine use as the primary risk factor in the Vancouver HIV-I epidemic. AIDS 2003;17:887-93.

Io. Fischer B, Rehm J, Kirst M, et al. Heroin-assisted treatment as a response to the public health problem of opiate dependence. Eur J Public Health 2002;12:228-34.

II. Health Canada. Reducing the harm associated with injection drug use in Canada. Ottawa: Health Canada; 200I. Available: www.hc-sc.gc.ca/ahc-asc/pubs/drugs-drogues /injection/index_e.html (accessed 2006 Oct 23).

Correspondence to: Dr. Mark A. Wainberg, McGill University AIDS Centre, Jewish General Hospital, 3755 chemin de la Côte Ste-Catherine, Montréal QC $\mathrm{H}_{3} \mathrm{~T}_{\mathrm{IE}}$; mark.wainberg@mcgill.ca
The complete picture on research.

PRACTICAL. RELEVANT. CMAJ IS NOW MORE COMPREHENSIVE THAN EVER.

CMAJ's reputation and wide Canadian and international reach make it THE place to publish leading Canadian research. CMAJ publishes important peer-reviewed research within weeks of submission and ranks fifth among international general medical journals by impact factor, a measure of the scientific importance of a journal.

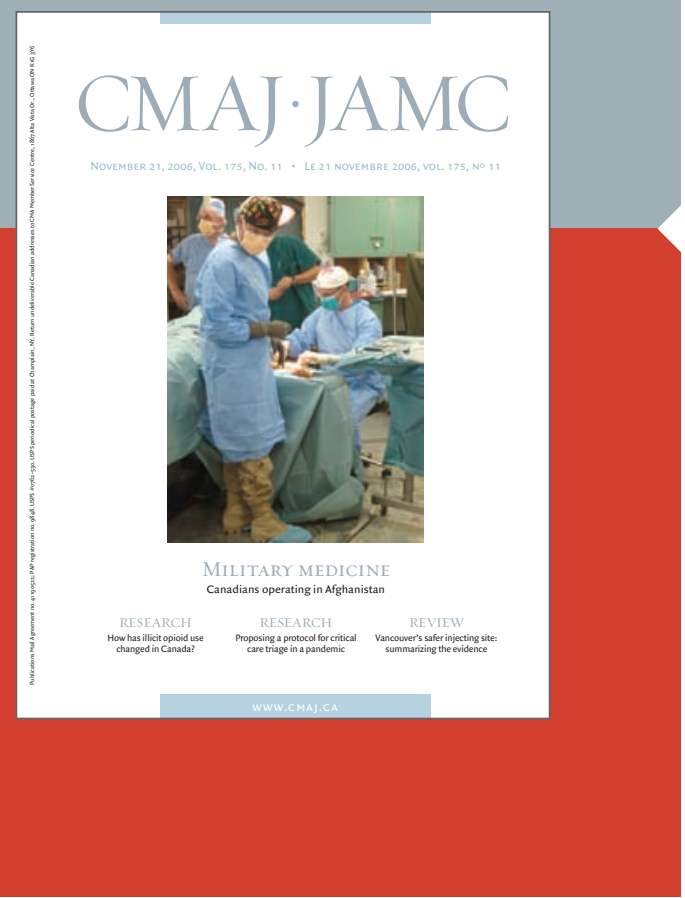

The essential read. ${ }^{\mathrm{TM}}$ 